\title{
On the Necessity and Approach of Inheritance of Liaoning Dialect Culture Inheritance
}

\author{
Shuan-jun An \\ College of International Exchange \\ Bohai University \\ Jinzhou, Liaoning, China \\ anshuanjun123@126.com
}

\author{
Cun-jiao Du \\ College of International Exchange \\ Bohai University \\ Jinzhou, Liaoning, China \\ 1170384211@qq.com
}

\begin{abstract}
Liaoning is located at the intersection of Han culture and Northern ethnic culture. It has rich dialect resources and the traditional culture behind dialects needs to be developed. The inheritance, the protection and its vigorous promotion of Liaoning dialect culture have a long-term cultural strategic significance for the protection of Liaoning's intangible cultural heritage. There are four major ways of inheriting Liaoning dialect culture: one is to establish a database of Liaoning dialect culture; the other is to carry out academic research on Liaoning dialect deeply; the third is to use the media to inherit the regional culture of Liaoning dialect; and the fourth is to use educational means to protect Liaoning dialect culture.
\end{abstract}

Keywords_Liaoning Dialect; Dialect Culture; Inheritance Approach; Education

On January 26, 2017, the "People's Daily" published the "Opinions on Implementing the Inheritance and Development Project of Chinese Excellent Traditional Culture" issued by the General Office of the CPC Central Committee and the General Office of the State Council (hereinafter referred to as "Opinions"), and the "Opinions" stated that: "Culture is the bloodline of the nation and is the people's spiritual homeland. Cultural self-confidence is a more fundamental, deeper, and more lasting force. The unique concept, wisdom, grace and charm of Chinese culture add to the confidence of the Chinese people and the Chinese nation's heart." ${ }^{[1]}$ When talking about the important task of "protecting inherited cultural heritage," "Opinions" pointed out: "We will vigorously promote and standardize the use of the national language, protect and inheriting dialect culture."[1] Dialect and dialect culture are two different concepts. Chinese dialect commonly referred to as local dialects, generally speaking, it has the characteristics as been used for a long time, been widely used by large population, and has a wide range of use. Dialects only used in some certain regions. Dialects are the carriers of dialect culture. Regional cultures were forming while dialects in certain regions were forming. Dialects embody the daily life, communication modes, migration history, local climate, geographical environment, natural resources, customs, and economic conditions of people of different nationalities or ethnic groups in different regions.

\section{The Necessity of Liaoning Dialect Culture INHERITANCE}

Liaoning is one of the 18 key provinces of the "One Belt and One Road" initiative. The "One Belt and One Road" initiative is a historical opportunity for the rejuvenation of the old industrial bases in the Northeast, and it is also an important opportunity to strengthen cultural exchange and cooperation with countries along the "One Belt and One Road". Since ancient times, Liaoning has been a place where the Han culture of the Central Plains and the cultures of the northern ethnic minorities border on and meet. It is one of the important birthplaces of the Chinese nation and the Chinese civilization. Liaoning has a wealth of language resources. Although it is in the northeast, Liaoning dialect differs from Heilongjiang and Jilin. Apart from Northeast Mandarin, there are Jiaoliao Mandarin and Beijing Mandarin. With the rapid changes and decline of dialects and regional cultures, how to timely and effectively tap and protect dialect culture has become an urgent issue in today's Chinese society, and this issue has aroused strong concern of the public. In this situation, the academic community should take active actions to organize and conduct substantive cultural surveys and preservation of dialects in a timely manner.

Judging from the current research, there are many writings on the Northeast dialect as a whole concept. Specifically, they can be divided into two major categories. One discusses the relationship between Northeast dialect and Northeast culture as a whole, such as "Northeastern Dialect and Culture" (Shikai Wang, Liying Yang), "View Northeast Culture from the Northeast Dialect” (Yin Liu), "The Relationship Between Northeast Dialects And Regional Cultures "(Lichun Sheng), "The Value of Northeastern Dialects in Regional Culture" (Beifang Gong), "The Interview between Northeastern Dialects and the Kanto Culture Relations "(Hongjie Wang), and "the Study on the Diversification of Northeastern Dialects.”(Shuang Liang) The other discusses the relationship between northeastern dialects and Northeastern culture in a specific area. For example, from the vocabulary research, there are "The Multi-Ethnic Culture of the Northeast from the Northeast Dialect words" (Ying Wang), "The Regional Culture in the Northeast Dialect Vocabulary" (Xiao Yu), and "The Regional Cultural Elements in the Animal Metaphor of the Northeast Dialect. "(Chuyang Qin), "Investigation and Study on the Usage of Idioms in Northeastern Dialect "(Hui 
Fang), etc. There are studies discuss the relationship between northeastern dialects and Northeastern culture in folk art, folk comedy and other fields such as "The Charm of Northeast Dialect in Northeast Folk Art" (Yanting Wang), "Northeastern Dialect in the Value of Folk Art and Culture” (Yanting Wang), "Northeast Folk Comedy in the Unique Charm of Dialect" (Xiaoxia Lu) and so on.

Dialects are of great significance to literature. The writer extracts nutrients from the dialect to shapes vivid characters, to display folk customs of the countryside, and to give readers a strong sense of local flavor, such as Beijing dialect in Lao She's novels and The Western dialect in the Shuli Zhao's "Little Two Black's Marriage", the Shandong dialect in Mo Yan's novels, the Hunan dialect in Shaogong Han's "Maqiao Dictionary", and the northeastern dialect in Zhaoming Dai's "Solitude in the Desert". The formulation of the syllabus should take into account the relationship between dialects and Putonghua, the internal laws and external conditions of language development, and the essence of Chinese language teaching in primary and secondary schools. It should also be discarded and focused on content selection.

As early as 2011, the "The 8th International Academic Conference on Regional Culture and Languages" sponsored by the Beijing Language and Culture University and Hanyang University in Korea discussed the "Chinese regional culture and the Northern Chinese language" as an important topic and called for academic attention to the relationship between dialects and regional culture. ${ }^{[2]}$ But from the current results, the description and exploration of Liaoning dialect culture is not very thorough. Although Liaoning is located in the northeast, as there are quite large the internal differences of the northeast, it needs to be carefully described and studied from the perspectives of language contact and language fusion.

In short, the investigation of dialects that are dying is imminent, and it is an urgent task to discover the hidden cultural connotations behind the dialects. Liaoning is located at the intersection of Han culture and Northern ethnic culture. It has rich dialect resources, and the traditional culture behind dialects needs to be developed. Chinese fine culture is the profound cultural soft power of the Chinese nation and the spiritual lifeline of the Chinese nation. Judging from the current research, there are many achievements dedicated to dialect studies, and the results of regional culture behind the exploration of dialects are not enough and not deep enough and it is necessary to conduct an in-depth investigation and collation.

\section{EFFECTIVE WAYS TO PROTECT AND INHERIT THE CULTURE OF} LIAONING DIALECTS

\section{A. Build Liaoning dialect culture database}

Organize teams, create survey programs, use scientific methods and modern techniques, investigate and collect reallife Liaoning dialect cultural materials, and interpret the collected vocabulary (including vocabulary, proverbs, etc.),record the dying thing or event in the form of a photograph or video, collect and record the intangible cultural heritage associated with the dialect such as Errenzhuan,
Chenpai Storytelling, Shenyang Crosstalk, Xiuyan Northeast Drum, and Anshan Storytelling, etc., collect classics that reflect the Liaoning dialect culture to build the "Liaoning dialect culture database”.

\section{B. Conducting in-depth academic research on Liaoning dialect}

The construction of corpora is to further study and in-depth digging into the connotation of dialect culture, and the work involved in this research requires firstly the relevant knowledge and skills of phonetics and phonology, and also the disciplines of culturology and folklore. Therefore, it is also necessary to pay attention to the training of related talents, especially high-level research talents. For example, the collation and publication of the colloquial language requires the accurate use of international tone to mark sounds, as well as the use of cultural and folklore knowledge.

\section{Using the media to inherit the geographical culture of Liaoning dialects}

The inheritance of dialect culture requires the space for natural survival and development of dialects. With the development of the Mandarin promotion work and people's increasing contact, the use of dialects has become increasingly narrow. It is necessary for local media to set up programs on dialect culture. As dialects are language formed in certain regions and historical environments, they record and carry the expressions of people's thinking and emotional appeals in the region. Dialects in radio and television programs can better show the charm of local culture and inspire people in the dialect area to have a strong imagination and sense of belonging.

\section{Using Educational Measures to Protect Liaoning Dialect Culture}

Dialects and cultures carried by dialects are important resources of the country and are an important part of Chinese culture. Faced with the gradual shrinking of the dialect space, it is necessary for primary and secondary schools to help students understand the diversity and richness of Chinese dialects through classroom teaching and experience the profoundness of Chinese culture. Of course, in the implementation process, we should correctly view and handle the relationship of dialects teaching with the promotion of Putonghua, clarify the purpose of dialects teaching: it is not the same as the teaching of Putonghua which ask students to learn phonetics, vocabulary and grammar systems, and then achieve the ability to use, but let students understand dialects, learn dialects and view dialects correctly. From the perspective of language acquisition theories, childhood is the best time to grasp dialects. Therefore, the best way to protect dialects is to ensure the space of use. Primary and secondary school education has the responsibility to undertake education and publicity of dialects so that students and parents can fully understand the importance of dialect culture and recognize the relationship between dialects and Putonghua. Primary and secondary school teaching don't have to systematically explain the structural system of dialects, but dialects can be used as materials in the teaching of Putonghua, allowing 
students to witness the greatness of Chinese language and stimulate their love for the language of the motherland. Dialects culture such as dialect vocabularies and other dialect forms as folk songs, nursery rhymes, dramas, etc., often contain rich cultures and are worth carrying out and inheriting in the classroom.

In the context of the information age, people are getting closer and more frequent, and there are more and more opportunities to speak Putonghua. There are two reasons for many families to want their generations to speak fluent Putonghua, one is to adapt to the times, and the second is to get rid of the "Rustic" temperament brought by dialects. This is obviously a misconception and a serious problem. Imagine it, if the most important positions of the dialect using been rooted out, what else can we do to save the dialect? Since elementary school, teachers should gradually let students to recognize the complexity of Chinese dialects and the diversity of regional culture, to understand the relationship between dialects and Putonghua is a matter of harmony and common prosperity, not contradictory. Dialects and Putonghua are precious resources for the Chinese nation. They are all worth studying. There is no difference between good and bad of the two. The people who are in the dialect area should be proud, confident of their ability to grasp dialects and Putonghua at the same time, but not be self-abasement. The protection of dialects requires the entire community to share responsibility. The few years before students entering primary school is a crucial period for their language acquisition. Government departments need to formulate relevant language policies and regulations and education departments and media workers should do well in propaganda work to help people understand the relationship between dialects and Putonghua. In the critical period of students' acquisition of language, as long as there is enough space and environment for learning, even if there are more languages or dialects, they can fully grasp. After the students enter primary school, the publicity work hand over to the majority of educators. It is necessary for the school to use the parent conference or other opportunities to further emphasize the relationship between dialects and Putonghua, emphasize the notion that languages are not good or bad to rouse parents' aware of seriousness and urgency of the dialect problem from the heart, consciousness and radically change such radical concepts as "using dialects is uneducated expression" and "speaking dialects is rustic". In the work of promoting Putonghua, some schools have failed to correctly understand the relationship between Putonghua and dialect, blindly emphasize the former, and even explicitly prohibit students from speaking in dialects on campus. This concept must be corrected.

Comparison of dialects and Putonghua, dialects, and ancient Chinese is an effective way of language teaching. For example, in the aspect of speech, the Middle Ages Yangsheng rhyme characters "Dang Kai San Zhuang" and "Jiang Kai Er ZhiZhuang" groups are basically read as a "closed mouth" in modern northern Chinese dialects, but in the southern dialect areas such as Hui, Wu, Xiang, Hakka, Gan, Ming, Cantonese, Pinghua dialects, etc. are basically read as "open call”. such as Jiangsu Yixing, Anhui Xiuning (Liukou Town), Hunan Chenxi, Hunan Guidong, Jiangxi Nanchang, Guangdong
Doumen, Guangxi Ningyuan, Inner Mongolia Erenhot and other places "Dang Kai San Zhuang" and "Jiang Kai Er ZhiZhuang” groups Converge to open calls "Zhang, Zhang, Zhuang, Zhuang, Chuang”, are all the same vowels. In the teaching of Putonghua, teachers should help students to summarize laws in a timely manner, categorize, summarize, and present these groups of words to students and allow students to familiarize them with dialects.

\section{CONCLUSION}

There are rich resources in Liaoning dialect, and the culture behind it is also abundant. It is necessary to explore effective methods and ways to protect and inherit. This article puts forward four ways of inheritance. It is suggested to combine dialects and regional cultures to study how Liaoning dialects reflect local cultural phenomena such as traditional culture and social customs in Liaoning, and to go back observe the formation and development of Liaoning dialects based on the generation and development of regional cultures. The inheritance and protection of Liaoning dialect culture and its vigorous promotion have a long-term cultural strategic significance for the protection of Liaoning's intangible cultural heritage. By tapping the hidden cultural connotations behind the Liaoning dialect, it is of great value to further enrich the traditional Chinese culture and enhance the cultural soft power of the Chinese nation.

\section{Project of the Fund}

Humanities and Social Sciences Planning Youth Fund of Ministry of Education: "The Differences and Evolution of ZhiZhuangZhangGroups of Dang-jiang She in Northern and Southern of Modern Chinese Dialects" (project number:16YJC740001); Liaoning Province Social Science Fund Project: "Liaoning Dialect Culture Excavation And Inheritance Research Under the Initiative 'One Belt, One Road"” (L17CYY004); Stage results of Dr Bohai university start the project: Pronunciation and combination type of ZhiZhuangZhang Groups of Dang-jiang She in the Modern Northern Dialects (project number: 0515bs004);The special task of China's language resources protection project: "Investigating of Chinese Dialect in Lingyuan, Liaoning" (project number: YB1806A003).

\section{REFERENCES}

[1] http://www.gov.cn/zhengce/2017-01/25/content_5163472.htm

[2] http://www.360doc.com/content/12/0201/23/3320305_183527836.shtml

[3] Shuguang Xu, Daming Zhang. Concise Dictionary of Northeast Dialect [Z]. Shenyang:Liaoning People's Publishing House, 1988(In Chinese).

[4] Sizhou Ma,Guanghui Jiang. The Northeast Dialect Dictionary [Z]. Changchun: Jilin Literature and History Press, 2005(In Chinese).

[5] Zhiping Nie. Vocabulary Research of Heilongjiang Dialect [M]. Changchun: Jilin People's Publishing House, 2005(In Chinese)

[6] Ying Wang. Looking at the Multi-ethnic Culture in the Northeast from the Northeastern Dialect Words [J]. Social Science Front, 2004 (01) (In Chinese).

[7] Rulong Li. Research on Dialects and Regional Culture[J]. Journal of Quanzhou Teachers College (Social Science Edition), 2005(01):50(In Chinese). 
[8] Rulong Li. Chinese Dialect Resources and Its Development and Utilization[J]. Journal of Zhengzhou University (Philosophy and Social Sciences Edition), 2008(1) (In Chinese).

[9] Rulong Li. Chinese Language Teaching and Dialect Investigation and Research[J]. Language Teaching and Research, 1997(2) (In Chinese).
[10] Yonghuan Wu. Significance and Countermeasures of Cultural Heritage Protection in Chinese Dialects[J]. Journal of Renmin University of China, 2008(4) (In Chinese). 